\title{
Impactos ambientais em Unidades de Conservação: Parque Nacional de Anavilhanas na visão dos profissionais envolvidos com a visitação
}

\section{Environmental impacts in Protected Areas: National Nark Anavilhanas in professionals vision involved with the visitation}

\author{
Bianca Costa Azevedo de Paiva
}

\begin{abstract}
RESUMO: Esta pesquisa tem como finalidade analisar quais os impactos ambientais causados pela visitação pública no Parque Nacional de Anavilhanas na percepção dos profissionais envolvidos. Visando o alcance dessa finalidade, foram elaborados os seguintes objetivos específicos: estudar as características das Unidades de Conservação, focando na categoria de Parques Nacionais; pesquisar a estrutura do Parque Nacional de Anavilhanas e seu uso público e relacionar o uso público do Parque Nacional de Anavilhanas com os impactos ambientais gerados, na percepção dos profissionais envolvidos. A método utilizado foi estudo de caso e quanto aos meios foram pesquisa de campo e pesquisa bibliográfica. Através da coleta de dado no local da pesquisa, foi possível apontar alguns impactos ambientais perceptíveis aos profissionais envolvidos com a visitação no Parque Nacional de Anavilhanas, tais como poluição em geral, mudança na rotina dos animais da localidade, degradação das trilhas, entre outros.
\end{abstract}

PALAVRAS-CHAVE: Impactos; Visitação; Anavilhanas.

\section{ABSTRACT}

The purpose os this research is toanalyze the environmental impacts of public visitation at the Anavilhanas National Park in the perception of the professionals involved. As an attempt to reach this goal, the following specific objectives were established: to study the characteristics of protected areas, focusing on National Parks category; searching the structure of the Anavilhanas National Park and its public use and relate the public use of the Anavilhanas National Park with the environmental impacts, as the perception of the professionals involved. The method used was the case study that was reached through search field and bibliographic research. By collecting data at the research point, it was possible to identify some environmental impacts perceptible to professionals involved in the visitation in Anavilhanas National Park, such as pollution in general, change in local animals routine, degradation of trails and others.

KEYWORDS: Impacts; Visitation; Anavilhanas. 


\section{Introdução}

Ao longo do tempo várias definições surgiram do que seja atividade turística. Barreto (1995) relata que esta definição se remonta a 1911, quando o economista austríaco Hermann Von Schullern Zu Schattenhofen escrevia que o turismo é o conceito que compreende todos os processos, especialmente os econômicos, que se manifestam na chegada, na permanência e na saída do turista de um determinado município, país ou estado.

No entanto, o conceito dessa atividade também pode variar de acordo com o enfoque da disciplina envolvida, podendo muitas vezes estar em extremos opostos. Todavia, vale ressaltar que uma das definições mais aceitas é dada pela Organização Mundial do Turismo - OMT (1999), onde a mesma define que o turismo compreende as atividades realizadas pelas pessoas durante suas viagens e estadias em lugares distintos de seu entorno habitual, por um período consecutivo e inferior a um ano, por motivos de férias, negócios e outros.

Em meados da década de 1970 deu-se início as primeiras concepções sobre questões ambientais e ao longo do tempo estas preocupações ganharam espaço em discussões e encontros internacionais, a partir desse momento, a atividade turística em ambientes naturais expandiu no mercado, pois o viajante entende a natureza como algo a ser desvendado, assim, esta ideia provoca no indivíduo o desejo de se expor a situações desconhecidas.

Mendonça (1999, p. 21) relata que a avaliação do meio ambiente pelo visitante é puramente estética, pois é a visão de um estranho e o estranho julga pela aparência, por algum critério formal de beleza. Porém, alguns ambientes naturais têm sido enormemente valorizados pela atividade turística, e proporcionam, de alguma forma, um contato mais direto com certos elementos naturais. É através desse contato mais direto com a natureza, que o turismo proporciona que é desenvolvida uma relação de troca, de aprendizado e de respeito entre visitante e natureza.

Uma forma de proporcionar este contato com o meio ambiente é a visitação que ocorre em Unidades de Conservação (UC), e Jesus (2002, p. 844) diz que é possível entender como visitação em Unidades de Conservação, as atividades recreativas, educativas e interpretativas, realizadas em contato com os atributos naturais e culturais, nas quais o principal objetivo é despertar no visitante, de forma lúdica, o respeito e a importância desses recursos.

Segundo o Instituto Chico Mendes de Conservação da Biodiversidade (ICMBIO) a categoria mais popular e antiga das UC's é a categoria de Parque Nacional, onde há possibilidade de maior interação entre o visitante e a natureza, pois permite o desenvolvimento de atividades recreativas, educativas e de interpretação ambiental, além de permitir a realização de pesquisas científicas.

O Arquipélago de Anavilhanas, localizado no Estado do Amazonas, nas proximidades do município de Novo Airão, desde o ano de 1981 já era 
uma área protegida em âmbito federal na categoria de Estação Ecológica, no entanto, mudou de categoria de unidade de conservação e passou a ser denominado Parque Nacional de Anavilhanas.

Devido ao fácil acesso a este parque e a proximidade de algumas cidades, o uso público da área é contínuo. Neste âmbito surge o seguinte questionamento: Quais os impactos ambientais causados pela visitação pública no Parque Nacional de Anavilhanas na percepção dos profissionais envolvidos?

Esta pesquisa tem como finalidade analisar quais os impactos ambientais causados pela visitação pública no Parque Nacional de Anavilhanas na percepção dos profissionais envolvidos. Visando o alcance dessa finalidade, foram elaborados os seguintes objetivos específicos: estudar as características das Unidades de Conservação, focando na categoria de Parques Nacionais; pesquisar a estrutura do Parque Nacional de Anavilhanas e seu uso público e relacionar o uso público do Parque Nacional de Anavilhanas com os impactos ambientais gerados, na percepção dos profissionais envolvidos.

Tendo em vista a indagação do pesquisador, juntamente com a percepção de pouco acervo bibliográfico sobre o Parque Nacional de Anavilhanas, surgiu a motivação da pesquisa. Acredita-se ainda, que este estudo enriquece o meio acadêmico, pois permite que o mesmo obtenha mais conhecimento sobre área investigada, como também amplia 0 conhecimento científico do tema, auxiliando nos estudos futuros.

\section{Metodologia}

O Parque Nacional de Anavilhanas abrange os municípios de Novo Airão e Manaus no estado do Amazonas, totalizando 400 ilhas aproximadamente. Foi criado originalmente como Estação Ecológica através do Decreto № 86.061, emitido em 2 de junho de 1981 e mediante Lei oo 11.799/2008, mudou de categoria, tornando-se Parque Nacional.

O Parque tem como diferencial a beleza natural da Floresta Amazônica e possibilidade de conhecer de perto a espécie de boto cor-derosa, considerado o atrativo maior da localidade.

O método escolhido nesta pesquisa foi o estudo de caso, pois buscou-se analisar um parque específico, denominado Parque Nacional de Anavilhanas. Trata-se de uma técnica utilizada em pesquisa de campo que se caracteriza por ser o estudo de uma unidade, ou seja, de um grupo social, uma família, uma instituição, uma situação específica, uma empresa, um programa, um processo, uma situação de crise, entre outros, com o objetivo de compreendê-los em seus próprios termos, ou seja, no seu próprio contexto (MICHEL, 2009).

Quanto aos meios foram utilizadas as pesquisas de campo e bibliográfica. Denomina-se de campo, pois houve o deslocamento da pesquisadora até o ambiente onde o estudo foi realizado. Ressalta-se que 0 material bibliográfico utilizado é composto de livros, periódicos e teses relacionados ao tema exposto. 
A pesquisa de campo, no ambiente natural, é particularmente importante na pesquisa social, apropriada para estudos de indivíduos, grupos, comunidades, organizações, sociedades, considerando que, para que a pesquisa social, mais importante que encontrar soluções e explicar os fenômenos, entender realidades, criando significados sociais (MICHEL, 2009).

Percebeu-se a pesquisa de ordem qualitativa, pois buscou-se analisar de forma profunda os impactos ambientais causados pelo uso público do Parque Nacional de Anavilhanas, mediante percepções dos profissionais envolvidos na visitação.

Para Goldemberg (1999) a pesquisa qualitativa é uma técnica específica, mas uma análise holística onde se procura reunir o maior número de informações detalhadas, por meio de diferentes técnicas de pesquisa, com o objetivo de aprender a totalidade de uma situação e descrever a complexidade de um caso concreto.

A amostra utilizada é não probabilística intencional, pois foram selecionados apenas os profissionais envolvidos na visitação do Parque Nacional de Anavilhanas como sujeitos da pesquisa. Conforme aborda Barros e Lehfeld (2007) a amostra não probabilística é aquela composta de forma acidental ou intencional, ou seja, os elementos não são selecionados aleatoriamente.

A coleta de dados ocorreu por meio de questionários com perguntas abertas e fechadas. O questionário é um formulário, previamente construído, constituído por uma série ordenada de perguntas de campo fechados e abertos, que devem ser respondidas por escrito e sem a presença do entrevistador (MICHEL, 2009).

Como análise dos dados compreende-se como discursiva, pois buscou-se analisar e descrever os impactos ambientais decorrentes da visitação no parque, de acordo com os sujeitos da pesquisa. Coriolano (2005, p.51) cita que a "análise de discurso implica buscar bases epistemológicas e conceituais que indiquem caminhos para a apreensão dos fenômenos estudados".

\section{Unidades de Conservação}

A lei que institui o Sistema Nacional de Unidades de Conservação SNUC, estabelece critérios e normas para a criação, implantação e gestão das Unidades de Conservação. Entende-se por unidade de conservação, segundo o SNUC, Art. 2ㅇ:

espaço territorial e seus recursos ambientais, incluindo as águas jurisdicionais, com características naturais relevantes, legalmente instituído pelo Poder Público, com objetivos de conservação e limites definidos, sob regime especial de administração, ao qual se aplicam garantias adequadas de proteção (BRASIL, 2000) 
Duas são as categorias de classificação das Unidades de Conservação, cada categoria possui ainda suas subcategorias. Em âmbito geral têm-se Unidades de Proteção Integral, cujo objetivo "é preservar a natureza, sendo admitido apenas o uso indireto dos seus recursos naturais, com exceção dos casos previstos na Lei" e Unidades de Uso Sustentável, com o objetivo de "compatibilizar a conservação da natureza com o uso sustentável de parcela dos seus recursos naturais".

As categorias que compõem o grupo de Unidade de Proteção Integral, são: Estação Ecológica, Reserva Biológica, Parque Nacional, Monumento Natural e Refúgio de Vida Silvestre. As duas primeiras categorias não permitem a visitação pública, exceto quando o objetivo é educacional, já as outras três, permitem a visitação mediante normas e restrições estabelecidas no Plano de Manejo de cada unidade.

O grupo de Unidades de Uso Sustentável é constituído por sete categorias, sendo elas: Área de Proteção Ambiental, Área de Relevante Interesse Ecológico, Floresta Nacional, Reserva Extrativista, Reserva de Fauna, Reserva de Desenvolvimento Sustentável e Reserva Particular do Patrimônio Natural. Em todas essas categorias é permitida a visitação pública, desde que a mesma aconteça respeitando o plano de manejo de manejo de cada unidade.

O pioneiro na criação de áreas naturais protegidas foram os Estados Unidos no final do século XIX, mesmo não existindo até aquele instante nenhum conceito de Unidades de Conservação, surgiu em 1872 o Parque Nacional de Yellowstone, sendo a primeira Unidade de Conservação do mundo. No entanto, Costa (2002) relata que o Presidente Abraham Lincoln decretou a área do atual Parque Nacional de Yosemite "inalienável em qualquer tempo" em 1864, tornando-se a primeira área de preservação.

A história das Unidades de Conservação brasileiras foi influenciada pelo caso de Yellowstone, em 1876 o político André Rebouças fez uma proposta de criação de Parques Nacionais nas áreas de Sete Quedas (PR) e da ilha do Bananal, nos rios Tocantins e Araguaia (TO). Porém, a primeira unidade de conservação só foi criada em 1937, o Parque Nacional de Itatiaia, tendo como base o Código Florestal de 1934, que estabeleceu os primeiros conceitos para Parques Nacionais, Florestas Nacionais e Florestas Protetoras.

Conforme o SNUC a categoria de Parque Nacional tem o objetivo básico a preservação de ecossistemas naturais de grande relevância ecológica e beleza cênica, possibilitando a realização de pesquisas científicas e o desenvolvimento de atividades de educação e interpretação ambiental, de recreação em contato com a natureza e de turismo ecológico. A visitação pública está sujeita ao plano de manejo, às normas estabelecidas pelo órgão responsável por sua administração, e àquelas previstas em regulamento.

Sendo assim, Costa (2002) defende a ideia que essas áreas possuem imenso valor patrimonial, pois seus recursos podem ser utilizados na melhoria da qualidade de vida humana, e como principal área de 
desenvolvimento do segmento do turismo que mais cresce no mundo atualmente: o ecoturismo.

Todo Parque Nacional é de posse e domínio público, sendo que as áreas particulares incluídas em seus limites serão desapropriadas, de acordo com o que dispõe a Lei do SNUC.

\section{Limite Aceitável de Câmbio (LAC): manejando e monitorando visitantes}

Considerando a irregularidade na distribuição dos recursos naturais, a rapidez com que eles foram explorados e, consequentemente, a raridade de alguns ecossistemas nas regiões mais populosas do país, não é difícil concluir que esta demanda pressionará as poucas Unidades de Conservação com alguma infraestrutura, exigindo mais áreas e, talvez, maiores facilidades.

Em relação ao uso público nas Unidades de Conservação, é possível ter como base modelos que já tiveram sucesso e que podem ser adaptados às nossas características e realidade do país. Um exemplo é o Sistema Limites Aceitáveis de Câmbio (LAC), considerando que qualquer uso produz no mínimo algum impacto, o Lac reconhece que as mudanças ocorridas em função do uso são inevitáveis e busca definir quanto de mudança será permitido, onde e quais ações de manejo são necessárias para controla-las.

Enquanto a capacidade de carga busca determinar quantas pessoas poderiam usar uma área sem causar danos, o LAC se preocupa com as condições desejadas e quanto de mudança pode ser tolerado em diferentes partes. Assim, a questão básica é que o processo LAC admite que o real interesse é o efeito do uso e não quanto de uso está ocorrendo (STANLEY et al., 1985; REED; MERIGLIANO, 1990).

O workshop "Manejo de Turismo em Áreas Protegidas" do IV Congresso Mundial sobre Parques Nacionais e Áreas Protegidas, ocorrido na Venezuela em 1992, destaca que a visitação em Unidades de Conservação deve servir como um instrumento para fomentar os objetivos das Unidades de Conservação, mantendo a integridade do ecossistema, a biodiversidade, a conscientização do público e a melhoria da qualidade de vida da população local.

No que se trata ao manejo e monitoramento do visitante, é necessária uma variedade de dados dos visitantes. Inicialmente dados de uso, como as informações básicas sobre a quantidade, formas e características de uso. Logo em seguida, os dados dos visitantes, como as características e comportamentos, desejos e preferências, a satisfação que resulta da visita, suas atitudes sobre as condições e sobre outros usos; suas reações prováveis às ações políticas e regulamentações de manejo. Todas essas informações mudam com o passar do tempo, porém, em função do custo, nem todas são monitoradas periodicamente. Os dados básicos devem ser coletados anualmente, outras informações dos visitantes precisam ser atualizadas em intervalos maiores (HENDEE et al., 1990). 
O comportamento indesejável do visitante pode ser enfrentado de duas formas básicas de manejo, de forma indireta, enfatiza influenciar ou modificar o comportamento, os visitantes possuem liberdade de escolha es administradores não controlam totalmente e, o de forma direta, enfatiza regras de comportamento; escolha individual restrita, alto grau de controle sobre os visitantes.

Sobre a importância da participação do público, Stokes (1990) afirma que é indiscutível que um adequado envolvimento e apoio do público no processo de planejamento garante a implementação do mesmo. Os administradores não devem apenas compreender as questões técnicas e científicas, eles devem também compreender o papel do público no manejo dos recursos.

\section{Manual de monitoramento e gestão dos impactos da visitação em Unidades de Conservação}

A procura por ambientes naturais para atividades recreativas e de lazer vem aumentando a cada ano em grandes proporções, sendo que, na maioria dos casos, o cenário ideal para este tipo de atividade se encontra em áreas naturais protegidas, principalmente dentro dos Parques.

Segundo Boo (1992), a população, principalmente urbana, vem buscando mais contato com ambientes naturais, aumentando consideravelmente a demanda pelas áreas naturais protegidas ou Unidades de Conservação.

Hoje, turismo, recreação ou lazer, são as principais atividades de uso público nas UC de proteção integral e, de acordo com Dourojeanni e Padua (in Magro, 2003), as atividades turísticas são vistas como uma grande oportunidade para a sustentabilidade econômica das UC brasileiras, mas reconhece também que, tanto o turismo como o ecoturismo, podem representar uma ameaça para a preservação do meio ambiente quando não forem bem conduzidos.

É evidente a importância da visitação nas Unidades de Conservação, em especial nos parques, contudo para garantir o sucesso e perpetuidade da condição das UC e necessário conhecer os impactos que a visitação pode causar a esses ambientes e, assim, evita-los, controla-los e minimizalos. Para tanto, não há estratégia melhor que a implantação de um sistema de monitoramento e gestão dos impactos da visitação. Alguns impactos que valem a pena serem citados são: impactos na água, impactos do solo, impactos na vegetação, impactos na fauna, impactos sociais, entre outros.

As primeiras ações de controle dos impactos da visitação foram focadas no conceito de capacidade de carga, originalmente aplicado em disciplinas de manejo de pastagens. Este conceito, para o caso do manejo da visitação, tem como premissas básicas verificar o número de visitantes que uma área pode tolerar, sem que ocorram impactos inaceitáveis aos recursos naturais e a experiência do visitante. 
Os métodos de planejamento da visitação atualmente utilizados caracterizam-se por serem dinâmicos. Sua ênfase esta na condição futura desejada, designada através da utilização de indicadores que descrevem as condições atuais, fazendo com que os padrões desejáveis para a intensidade dos impactos nos recursos naturais ou na experiência do visitante, sejam alcançados através de ações administrativas.

Alguns indicadores podem ser considerados para mensurar os impactos da visitação: largura da trilha, número de trilhas não oficiais, danos aos recursos naturais, danos à infraestrutura, alteração do comportamento animal, problemas de drenagem, presença de lixo e a experiência do visitante.

\section{Análise dos dados}

A coleta de dados desta pesquisa ocorreu por meio de questionários aplicados com profissionais ligados a visitação do Parque Nacional de Anavilhanas, no dia 26 de Janeiro de 2014 no município de Novo Airão. Foram totalizados 18 questionários preenchidos por profissionais de diferentes setores de serviços prestados ao visitante.

Todos eram residentes do município de Novo Airão e a idade desses profissionais varia, sendo que a maioria possui idade entre 18 e 25 anos e do total de questionários validados metade eram do sexo masculino e metade do sexo feminino.

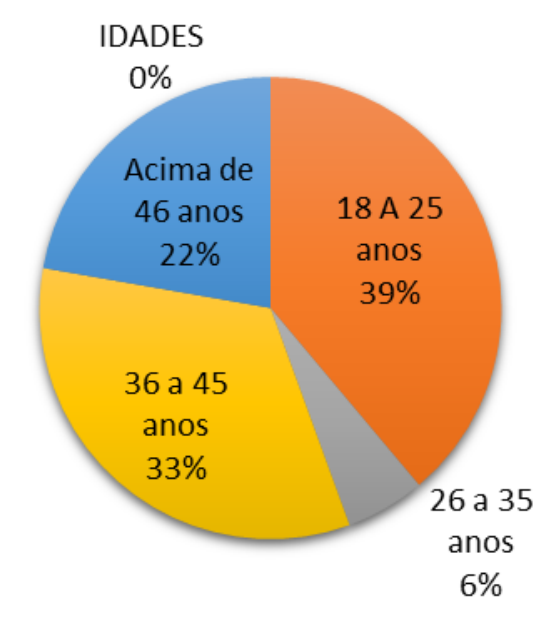

Figura 1: Idade dos participantes.

Figure 1: Age of participants.

Em relação ao grau de escolaridade, foram identificadas 4 pessoas com o ensino fundamental incompleto e $4 \mathrm{com}$ ensino fundamental completo, o ensino médio completo foi composto por 6 pessoas, ensino superior por 2 e não alfabetizado por 2 indivíduos.

Quando questionados se já conheciam o Parque Nacional de Anavilhanas apenas um indivíduo respondeu negativamente, no entanto, 
todos consideram o Parna importante para a economia da cidade e para meio ambiente.

O Parque Nacional de Anavilhanas possui uma estrutura simples para visitação, os sujeitos da pesquisa relataram que muita coisa ainda precisa melhorar quanto a estrutura física e qualificação dos profissionais envolvidos. Na localidade não existe nenhuma espécie de alojamento ou mirante para os visitantes. $O$ transporte na maioria das vezes é realizado por canoeiros autorizados por uma associação do município e são eles mesmos que fornecem as informações do Parna durante a visita, sem deixar de se preocupar com a segurança durante o percurso. Existe ainda a situação de pacotes fechados por agências, que já é oferecido uma estrutura com mais conforto e segurança por serem embarcações maiores.

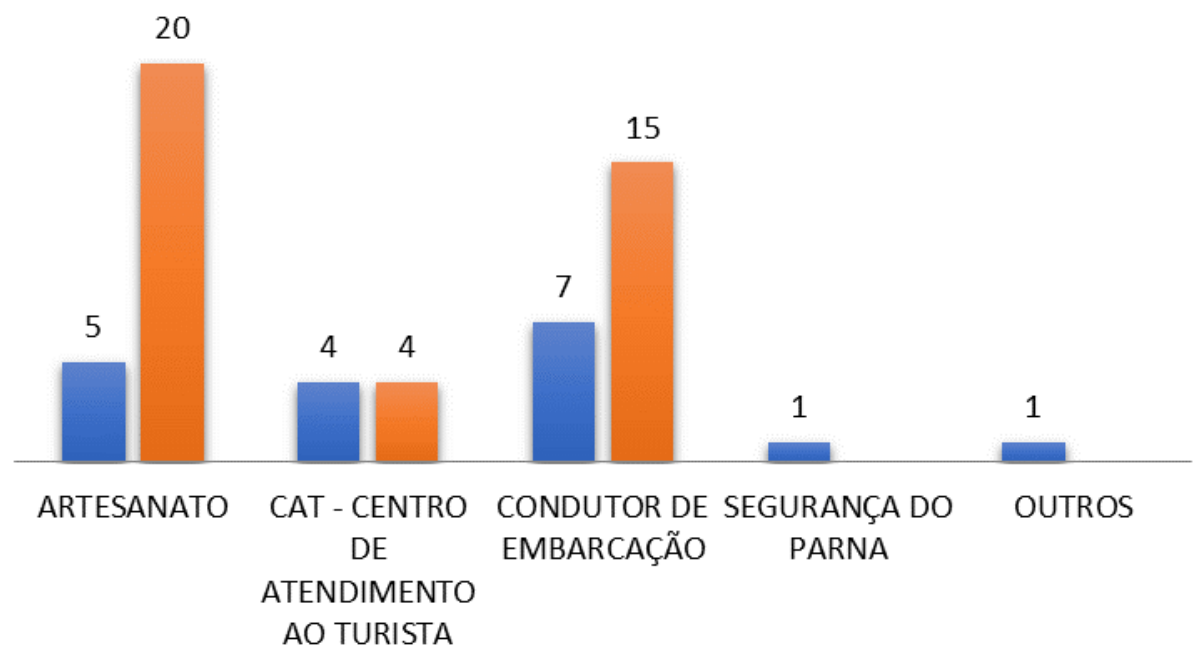

Figura 2: Setores de aplicação da pesquisa.

Figure 2: Sectors of research application.

Foram atingidos quatro setores que estão ligados direta ou indiretamente a visitação no Parque e o total de 12 pessoas concordaram que a visita pública traz mais vantagens ao local, pois o fluxo contínuo de pessoas inibiu a extração de madeira e pesca predatória. No entanto uma minoria relatou que os animais das proximidades ficam assustados devido a intensa movimentação no Parque.

No que diz respeito aos impactos ambientais perceptíveis que essa visitação causa, foram unânimes respostas relacionas a poluição em geral, principalmente as causadas por embarcações maiores que incluem o Parna em seu roteiro de visitas. Também foram citadas mudanças na rotina dos animais da região e degradação das trilhas existentes. No entanto, houve ainda um relato que dizia "depois que a área virou parque nacional, a poluição diminuiu bastante".

Na percepção dos sujeitos dessa pesquisa, os visitantes do Parna já apresentam alguma preocupação relacionada ao meio ambiente e quando 
embarcam para o percurso também são orientados da importância de manter aquela localidade conservada.

\section{Considerações finais}

Devido a localização próxima da cidade de Manaus e Novo Airão, o parque tem um fluxo constante de visitantes durante todo ano. $\mathrm{O}$ visitante tem a possibilidade de fazer o percurso de trilhas aquáticas de igapó durante a época de cheia do Rio Negro e desfrutar das praias na época da seca.

No entanto, qualquer outra estrutura de apoio ao visitante do Parque Nacional de Anavilhanas não está disponível ou não existe, por isso, as condições de visita ainda precisam sofrer melhorias para oferecer mais conforto e segurança.

Acredita-se que a incidência de poluição causada por embarcações maiores diminuiria caso houvesse controle mais rigoroso da visitação, porém, como o ordenamento do uso público do Parque ainda está em andamento muitas embarcações realizam o percurso sem nenhuma fiscalização constante.

Percebe-se a fiscalização mais rigorosa nas atividades que envolvem o contato com os animais da localidade, tais como atividades ligadas ao contato com botos cor-de-rosa, animais que sofreram mudanças na sua rotina habitual depois que houve aumento relevante de visitação.

Diante do que foi apresentado nos resultados desta pesquisa, é possível notar que o objetivo do estudo foi alcançado, pois mediante informações coletadas no questionário de pesquisa, foram pontuados alguns dos impactos ambientais percebidos pelos profissionais que trabalham de forma direta ou indireta com a visitação do Parque Nacional de Anavilhanas.

\section{Referências}

BARRETTO, M. Manual de iniciação ao estudo do turismo. Campinas: Papirus, 1995.

BARROS, A.J.P.; LEHFELD, N.A.S. Fundamentos de Metodologia Científica. Ed. São Paulo: Pearson Prentice Hall, 2007.

BRASIL, Presidência da República. Lei n. 9.985 de jun 2000. Regulamenta o art. 225, parágrafo 1‥, incisos I, II, III e IV da Constituição Federal, institui o Sistema Nacional de Unidades de Conservação da Natureza e dá outras providências.

CORIOLANO, L.N.M.T. Epistemologia da análise do discurso no turismo. Caderno Virtual de Turismo, vol. 5, núm. 2, 2005, pp. 50-56. Universidade Federal do Rio de Janeiro. Río de Janeiro, 2005.

COSTA, P.C. Unidades de Conservação. São Paulo: Aleph, 2002.

GOLDEMBERG, M. A arte de pesquisar. 3. ed. Rio de Janeiro: Record, 1999. 
JESUS, F. Plano de uso público - necessidade de atualização no planejamento. Anais do III Congresso Brasileiro de Unidades de Conservação. Fortaleza: Rede Nacional Pró- Unidades de Conservação: Fundação o Boticário de Proteção à Natureza: Associação Caatinga, 2002.

LOBO, A.C.; SIMÕES, L.L. (org.). Manual de Monitoramento e Gestão dos Impactos da Visitação em Unidades de Conservação. Governo do Estado de São Paulo por meio da Secretaria de Estado de Meio Ambiente. Disponível em: http://www.wwf.org.br/?27544/Manual-de-Monitoramento-eGestao-dos-Impactos-da-Visitacao-em-Unidades-de-Conservacao

MENDONÇA, R. Turismo ou meio ambiente: uma falsa posição. In: LEMOS, A.I.G. [org.] Turismo: impactos socioambientais. 2.ed. Editora Hucitec - São Paulo, 1999.

MICHEL, M.H. Metodologia e Pesquisa Científica em Ciências Sociais.2 ed. São Paulo: Atlas, 2009.

OMT. Sustainable development of tourism anan notated bibliography. Madrid, 1999.

SIMÕES, E.; WADT, F.; CORREARD, J.M. Programa de Uso Público no Núcleo Picinguaba. Anais do III Congresso Brasileiro de Unidades de Conservação. Fortaleza: Rede Nacional Pró-Unidades de Conservação: Fundação o Boticário de Proteção à Natureza: Associação Caatinga, 2002.

TAKAHASHI, L.Y. Limite Aceitável de Câmbio (LAC): manejando e monitorando visitantes. Anais do Congresso Brasileiro de Unidades de Conservação. Curitiba: IAP: UNILIVRE: Rede Nacional Pro Unidade de Conservação, 1997.

Bianca Costa Azevedo de Paiva: Universidade do Estado do Amazonas, Manaus, AM, Brasil.

E-mail: biiancapaiiva@hotmail.com

Link para o currículo Lattes: http://lattes.cnpq.br/2309775135271282

Data de submissão: 29 de outubro de 2016

Data de recebimento de correções: 17 de dezembro de 2018

Data do aceite: 17 de dezembro de 2018

Avaliado anonimamente 